$$
\begin{gathered}
D \circ E / E W / 12823--T / \\
=C M R / 95-239
\end{gathered}
$$

\title{
Groundwater Model Calibration at Pantex Using Data Fusion Modeling
}

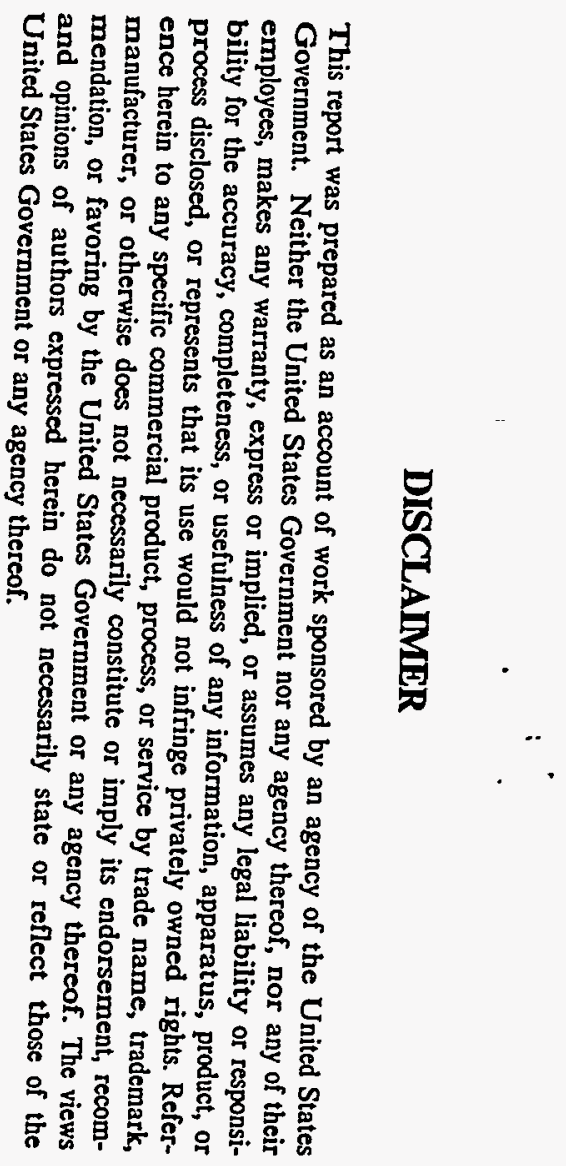

\section{for \\ Department of Energy}

EM-50

\section{Coleman Research Corporation 9891 Broken Land Parkway -}

Columbia, Maryland 21046

301-621-8600

RECEIV

APR 4996

, OST! 


\section{DISCLAIMER}

\section{Portions of this document may be illegible in electronic image products. Images are produced from the best available original document.}




\section{GROUNDWATER MODEL CALIBRATION AT PANTEX USING DATA FUSION MODELING}

\section{Introduction}

The U.S. Department of Energy (DOE) Pantex plant is located near Amarillo in the panhandle region of Texas. This Southern High Plains region is a well-defined plateau that slopes gently toward the southeast. Surface soils in this region are primarily clays and clay loams. The climate is arid with an average 18 to 19 inches of precipitation per year. The regional land surface is characterized by numerous playa basins that vary in diameter from a few hundred feet to one mile. Water accumulates in these depressions following heavy rains. Most of the playa water evaporates but a portion percolates downward to provide groundwater recharge. The playas may be related to geologic structural depressions caused by faulting in the area.

Regional hydrogeology is characterized by two principal aquifers: an upper zone (commonly referred to as the perched aquifer) at a depth of 200 to 300 feet below the Pantex site, and the deeper, thicker Ogallala aquifer whose base ranges from 650 feet to 900 feet below the site. A layer of fine-grained sediments, termed the Fine-Grained Zone (FGZ) generally occurs between the perched and Ogallala aquifers and acts as an aquitard (flow restriction zone) between the two. The Ogallala aquifer is the main water supply in the Southern High Plains, and pumping from this exceeds recharge.

The Pantex plant has operated as one of the Federal government's key conventional and nuclear weapons facilities since the 1940's. The plant has been used for fabrication of chemical high explosives and components of nuclear weapons. Contaminants from various waste products and processes at the plant have percolated into the perched groundwater zone berieath the plant and have migrated laterally with flowing groundwater in that zone. The perched aquifer is not used for drinking water or agricultural purposes. Also, there is no evidence of contamination in the Ogallala aquifer. In recent years, the DOE has expended considerable effort to characterize the nature and extent of groundwater contamination associated with the site. That effort is still on-going with the ultimate aim of determining and implementing appropriate remedial measures.

The goal of the study described in this report was to use 'Data Fusion modeling to calibrate a groundwater model near Zone 12 of Pantex, primarily to define the potential pathways to the Ogallala aquifer. Data Fusion is a new approach for combining different but interrelated types of information from multiple sources into a quantitative analysis of system characteristics and dynamic behavior. The Data Fusion Workstation (DFW) is a patented technique for carrying out Data Fusion analyses using specially developed computer based approaches. The technique results in the development of a calibrated model of a site consistent with the data, first principles, and geostatistical spatial continuity. A more explicit description of the Data Fusion concept and approach is presented below. 


\section{Data Fusion Modeling}

Engineering projects involving hydrogeology are often driven by uncertainties. For activities such as environmental remediation cost effective solutions often depend on the confidence with which the hydrogeology is known. For example, to create a groundwater contamination plume capture zone, answers are needed to questions about the number, depth, location and pumping schedules for extraction wells. Computer simulation based on hydrogeological models provides answers. In theory, simulation can provide real-time monitoring of remediation so a plume can be seen as it is being cleaned up. But simulation is only as good as its geological and parametric inputs. The earth is very heterogeneous, and typical data sets are fragmented and disparate so there are substantial uncertainties.

Currently, technical professionals usually do not have adequate tools to quantify uncertainty so they often rely solely on professional judgment to build in sufficient safety margins. This tends to lead to overly conservative decisions that waste money. Data Fusion modeling has value added as an engineering decision tool that quantifies uncertainty. Models are used in two different ways. First, models provide physical and statistical relationships between fragmented and disparate data sets, and fusion uses these relationships to extract geological and parametric information from the data. Second, models are used in computer simulation of remediation (e.g., to see contaminant plume movement) where the simulation is based on geological and parametric inputs. Data Fusion modeling can become even more useful as new technology provides additional data sources. This has already happened in numerical weather prediction and physical oceanography where fusion techniques are well established under the name of data assimilation as explained by McLaughlin in Reference 2.

With reduced cleanup budgets and greater reliance on risk assessment using predictive models with quantified uncertainties, Data Fusion modeling is a technology for the times. Using Data Fusion modeling, decision makers have a quantitative basis for decisions and action so the following benefits can be realized.

The utilization of existing data sets can be maximized to avoid cost of unnecessary new data acquisition.

- Data worth can be established in the field in real time during data acquisition to determine if reduction in uncertainty pays for the cost of acquisition.

- Remediation can be optimized in the computer to get it right with quantified safetymargins before it is done in the earth.

- $\quad$ Contaminant plumes can be monitored and seen in real time while they are being cleaned up.

- A basis is provided for quantitative cost reduction/avoidance. 
Data Fusion modeling has a solid foundation in the hydrogeological community. In Reference 1, Freeze, Massman, and Smith published a framework for hydrogeological decision analysis. They describe a pragmatic engineering approach to decision making that balances benefits, costs, and uncertainties. Their viewpoint and approach have been adopted in Data Fusion modeling as shown in Figure 1. Data Fusion quantifies geological and parametric uncertainty (such as hydraulic conductivity). As shown in Figure 1, hydrogeological simulation is performed (e.g., to observe plume movement) using geological and parametric inputs. Fusion propagates geological and parametric uncertainties through the simulation so the statistical confidence is quantified. Reliability uncertainties in the engineered components of remediation also enter into decisions, but the hydrogeological uncértainties usually dominate.

A fusion-type method known as data assimilation has become well established over several decades in numerical weather prediction and physical oceanography. But it is limited for hydrogeology because of the great numerical demands as explained by McLaughlin in Reference 2. Data Fusion modeling resolves the numerical limitations.

Data Fusion is a way of working backwards through models (inverse modeling) to quantify uncertainty. The new computational technology is an outgrowth of contributions over the last 25 years to space science, defense and intelligence communities. By making inverse modeling practical, Data Fusion is able to extract information from data that would otherwise be lost. Some have called this computational intelligence. We are literally telling the computer first principles and statistical models that provide relationships between fragmented and disparate data. We ask the computer to work backwards from the data through the models (inverse modeling) to determine or estimate what is in the earth and with what uncertainty. Then we ask the computer to use what is known about the earth to tell us where the contaminant plume is going (simulation).

\section{Pantex Model Calibration}

Figure 2, from the U.S. Army Corps of Engineers report in Reference 3, shows the Pantex region and the location of wells. The location of Zone 12 of the plant is also shown in the figure. Zone 12 is of special interest because it is an area where plant activities generated considerable wastes that may have contributed to explosive-related contaminants (such as $\mathrm{RDX}$ ) in the perched aquifer. Monitoring wells near the plant which reach the perched water but may or may not penetrate the FGZ are also shown. These wells monitor the contamination in the perched water. Principal playa areas on the site are also shown. . For reference purposes, the outlines of Zone 12 and the playas are shown in Figures 3 through 6 that display fusion results.

We relied heavily on data and information contained in the U.S. Army Corps of Engineers report of Reference 3 and the Argonne National Laboratory report of Reference 4. In addition, approximately 30,000 pages of data from a variety of sources were reviewed for relevant data. This included well logs, geologic and hydrogeologic framework studies, seismic interpretations, water level measurements, slug tests, and geotechnical and analytical chemistry laboratory analyses. These were reviewed to develop a hydrological modeling framework for inverse modeling using Data Fusion. 
Because the saturated thickness of the perched zone is relatively thin (varying from 0 to 60 feet), it is necessary to map the top of the FGZ in order to compute the flow within the aquifer. Data available for mapping the FGZ consisted of the lithologic and geophysical logs from about 50 wells around the Pantex area. These data tend to be clustered in the south-eastern and northern sectors of the modeled area (Figure 3). The elevation at the top of the FGZ was estimated using the Data Fusion software where the spatial continuity model assumed a statistical variation of 30 feet with a horizontal correlation distance of 2000 feet. Because the quality of the well $\log$ data varied significantly, the accuracy of the depth measurement was assumed to vary from 3 to 20 feet. Figure 3 shows the resulting top of FGZ estimate. Large variations in the surface elevation are apparent as are the large areas with no wells that have a corresponding large uncertainty in the estimate (as great as 45 feet). A channel in the top of the FGZ running generally southeast is apparent in the vicinity of Zone 12 .

Because there are no natural hydrological boundaries around the Pantex area, it was necessary to extend the region of the hydrological model far outside Pantex. This greatly reduces the sensitivity of the flow to the boundary conditions at the perimeter of the model. The extent of the model was approximately 100,000 by 100,000 feet on a variably spaced 32 -by-34 grid. There are no wells intersecting the top of the FGZ outside Pantex. Therefore, significant extrapolation was necessary to extend the top of the FGZ shown in Figure 3 to the larger area. This was done the following two different ways to determine sensitivity to the extrapolation: 1) assuming that the average FGZ slopes 2 feet per thousand downward to the southwest and 2) assuming that it is flat. The resulting flow estimate within the Pantex area was relatively insensitive to the assumed slope outside Pantex. Results presented here used the flat assumption.

The data available for hydrological modeling consists of 37 perched water level measurements and several hydraulic conductivity (slug) tests. Because the primary goal was to model the flow of perched water, simplifying assumptions which have little effect on the perched water flow were used. A two layer model was assumed in which the perched water was treated as an unconfined aquifer with the FGZ acting as a low-permeability layer separating the FGZ from the underlying Ogallala aquifer. For convenience in the model, the Ogallala was treated as a confined aquifer. In reality, however, it behaves more as an unconfined aquifer. This simplifying assumption has no significant effect on perched water flow. Recharge was included for playas and inter-playa areas but higher rates were specified for the playa areas. Also, vertical groundwater movement was allowed to be greater beneath- the playa areas. Since little information on flow in the larger region was available, the outer boundary of the model was assumed to be a no-flow boundary for the perched aquifer layer. Head dependent flow boundaries were used for the eastern and southwestem Ogallala boundaries. The Amarillo well field was modeled as a flux of 410 million cu-ft/year which is the approximate current pumping rate.

The hydrological fusion uses a steady-state finite-difference flow model which is similar in many respects to the U.S. Geological Survey MODFLOW model and is called MODLIKE. The most significant differences involve the method by which variations in conductivity are handled (MODFLOW assumes discontinuities while fusion assumes smooth variations between nodes) and the method for handling the variable water level in cells of an unconfined aquifer 
(fusion never lets cells become completely dry). This latter difference is probably the most significant since it allowed fusion to compute a solution for hydraulic conditions for which MODFLOW could not compute a solution. Similar fusion results have been obtained using a variably saturated model called VAM3D from HydroGeoLogic, Inc., validating the MODLIKE assumptions.

Fusion models the log hydraulic conductivity as a spatially correlated stochastic process with a systematic trend as advocated by Freeze et. al. in Reference 1. For this model, the standard deviation in log hydraulic conductivity was assumed to be 0.4 with a 2000 foot correlation distance. The correlation distance is the distance beyond which the hydraulic conductivity is not substantially correlated. The average measured conductivity of the Ogallala is about $10,000 \mathrm{ft} /$ year.

In order to minimize the sensitivity of the computed perched water flow to modeling assumptions, fusion was allowed to estimate critical parameters of the model. In addition to estimation of the head and log hydraulic conductivity at each node, fusion estimated the recharge in playa 1 , and the vertical groundwater movement for the entire region, the Pantex region, and the four playas. Playa 1 was treated differently because the wastewater discharge from Pantex operations (originally drawn from the Ogallala aquifer) is channeled to playa 1. Recharge for the entire region (except Pantex) was set to the average listed in several studies, 2.4 in/year. Recharge within playas 2 through 4 was assumed to be 6.7 in/year based on studies of the area.

Fusion was run with different setups specifying different conceptual models and different variables to be estimated. For example, the vertical groundwater movement for playa 1 was originally the same as for the other playas, but the converged fusion results suggested treating playa 1 differently. Even though the estimation is highly nonlinear (principally because of the variable water elevation in the perched aquifer) fusion produced a converged numerical model in only 8 or 9 iterations (approximately 15 minutes of SGI Indigo II time) for a given conceptual model.

Conventional manual calibration methods require hand tweaking of the numerical model for each conceptual model that is considered. In general, manual calibration can take days or weeks for a given conceptual model and there is no objective way to know if the calibration has converged. If it appears that the conceptual model should be changed, then the whole process needs to be laboriously repeated. The rapid convergence provided by Data Fusion replaces the slow hand tweaking. This frees the hydrogeologist to focus on the scientific and engineering issues of getting a good conceptual model rather than being burdened by tweaking yet another numerical model.

Figures 4-6 show the estimated head contours and flow pathlines, log hydraulic conductivity, and.head fit residuals. As shown in Figure 6, a good fit was obtained between the fusion model results and the field data. The RMS head residual is only 0.4 feet. Figure 5 shows the fusion estimates for heterogeneity in hydraulic conductivity. As explained by Freeze et. al. in Reference 1, modeling of hydraulic conductivity heterogeneity is critical for confident groundwater modeling. Flow pathlines shown in Figure 4 are determined with confidence within 
the region of data coverage. Pathlines on the boundaries of the data coverage are sensitive to model boundary conditions and need additional data acquisition to be determined with confidence. Also, the data were not available for this study to separate recharge and vertical groundwater movement since a model can be calibrated with a low value of one as long as the other is low and vice versa. With more information that should be available about recharge, vertical groundwater movement could be separately estimated.

The flow pathlines shown in Figure 4 emanate from playa 1 at the top of the figure due to mounding of water under the playa from plant wastewater discharge to the playa. Water flowing south from playa 1 tends to part around Zone 12 with the bulk of the flow to one side or the other of Zone 12 but not directly through Zone 12. Then the flow bends to the east in the direction of the channel in the top of the FGZ aquitard before it comes to the boundary of the data coverage. As additional data is acquired to the east, it is anticipated that it will be found that the flow continues to the east. Since fusion converges so rapidly, fusion could be used to update flow models in the field to provide real time guidance for site investigation.

\section{Conclusions}

A groundwater model was calibrated for a perched aquifer under Zone 12 at Pantex using hydraulic head data, slug tests, and recharge information. The MODLIKE numerical model that is similar to the USGS MODFLOW model was validated by comparison with the variably saturated VAM3D model from HydroGeoLogic, Inc. A good model fit was achieved with an RMS head residual of only .4 feet. Hydraulic conductivity heterogeneity was estimated in order to provide flow pathlines with confidence within the region of data coverage.

As the conceptual model was modified to improve results, fusion converged rapidly for each conceptual model. Generally it took 8 or 9 numerical iterations at approximately 15 minutes of Indigo II time. This means that fusion modeling is fast enough to be used for real time field model updating. This provides a capability that has never before been possible with conventional manual model calibration.

As additional data is gathered to the east of Zone 12, Data Fusion modeling could be used to provide guidance of site investigation. Flow models could be updated in real time in the field to support decisions about placement of future borings. Further, acquisition of additional information about recharge would allow fusion to provide understanding about the separation of recharge and vertical groundwater movement effects. 


\section{References}

1. Freeze, R.A., J. Massmann, L. Smith, T. Sperling, B. James, "Hydrogeological Decision Analysis: 1.A-Framework", Groundwater, Vol. 28, No. 5, 1990.

2. McLaughlin, D., "Recent Developments in Hydrologic Data Assimilation", Prepared for U.S. National Report to the IUGG, June 1994.

3. "Pantex Plant Groundwater Sampling Report August 1994 Sampling Round," U.S. Army Corps of Engineers, Tusa District, March 1995.

4. "Draft Phase I Report and Phase II Work Plan: Expedited Site Characterization for the DOE Pantex Zone 12 Groundwater Investigation," Argonne National Laboratory, September 1994. 


\section{Figure 1: Data Fusion Role In Decision Analysis}

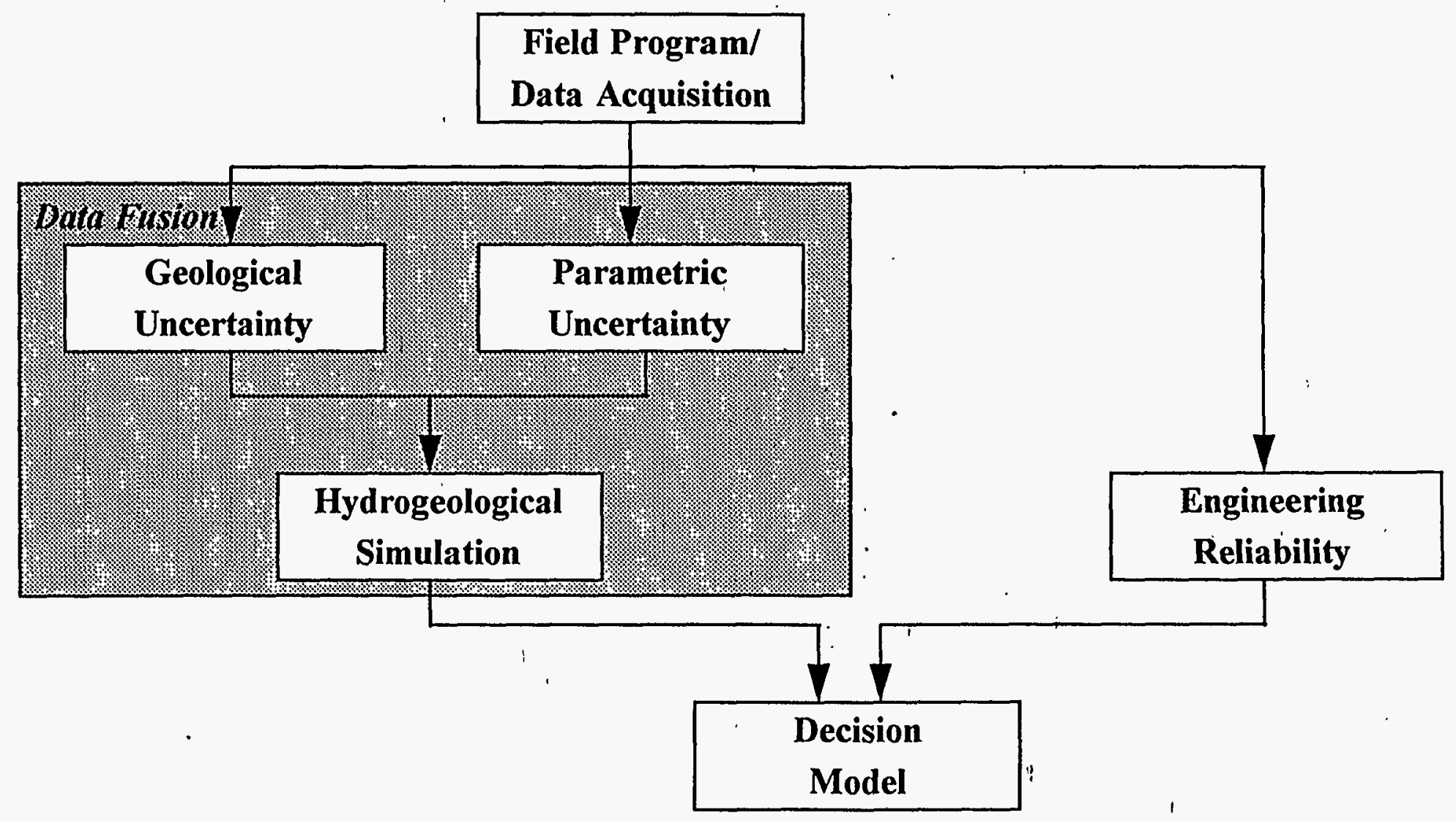

CRC Coleman Research 


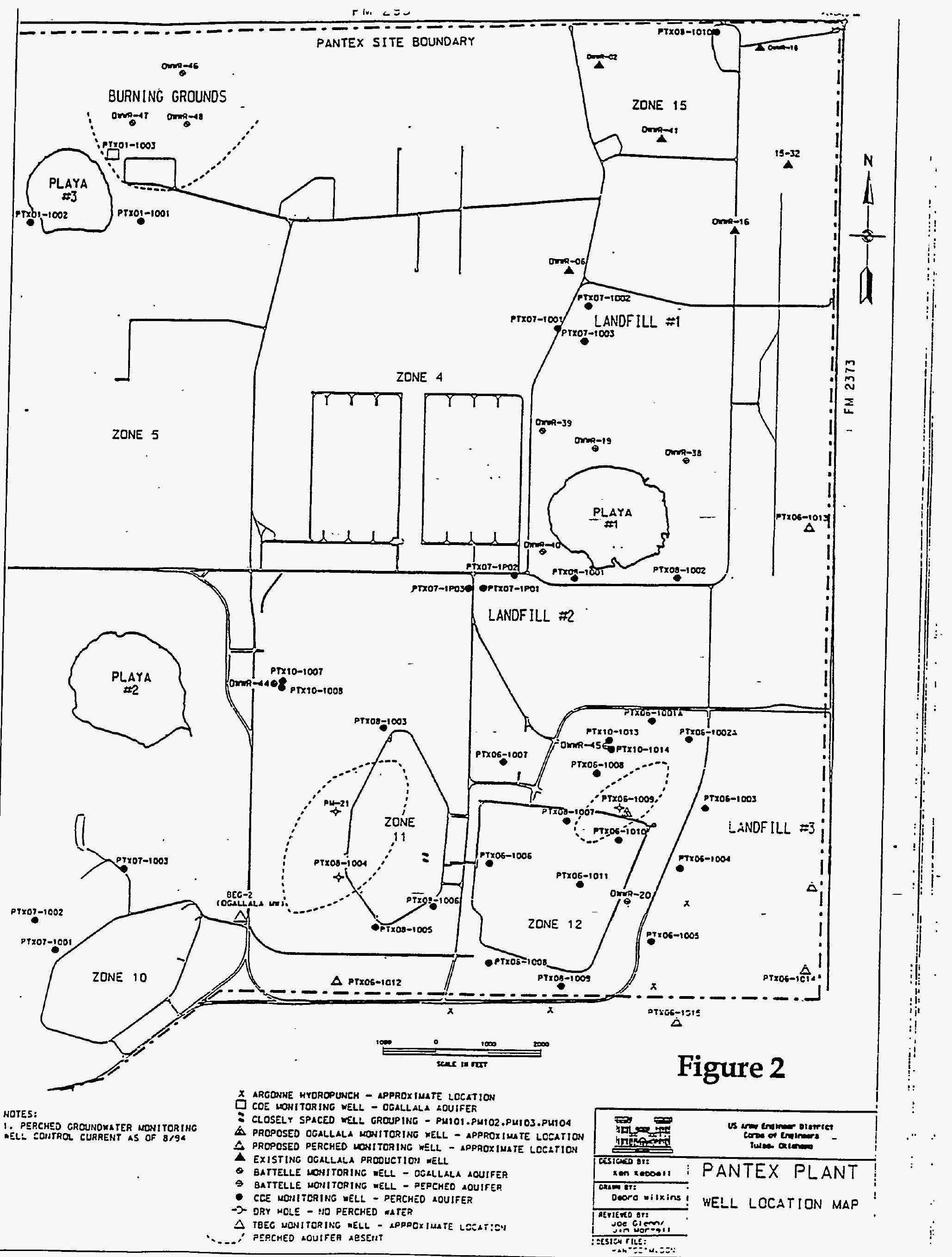




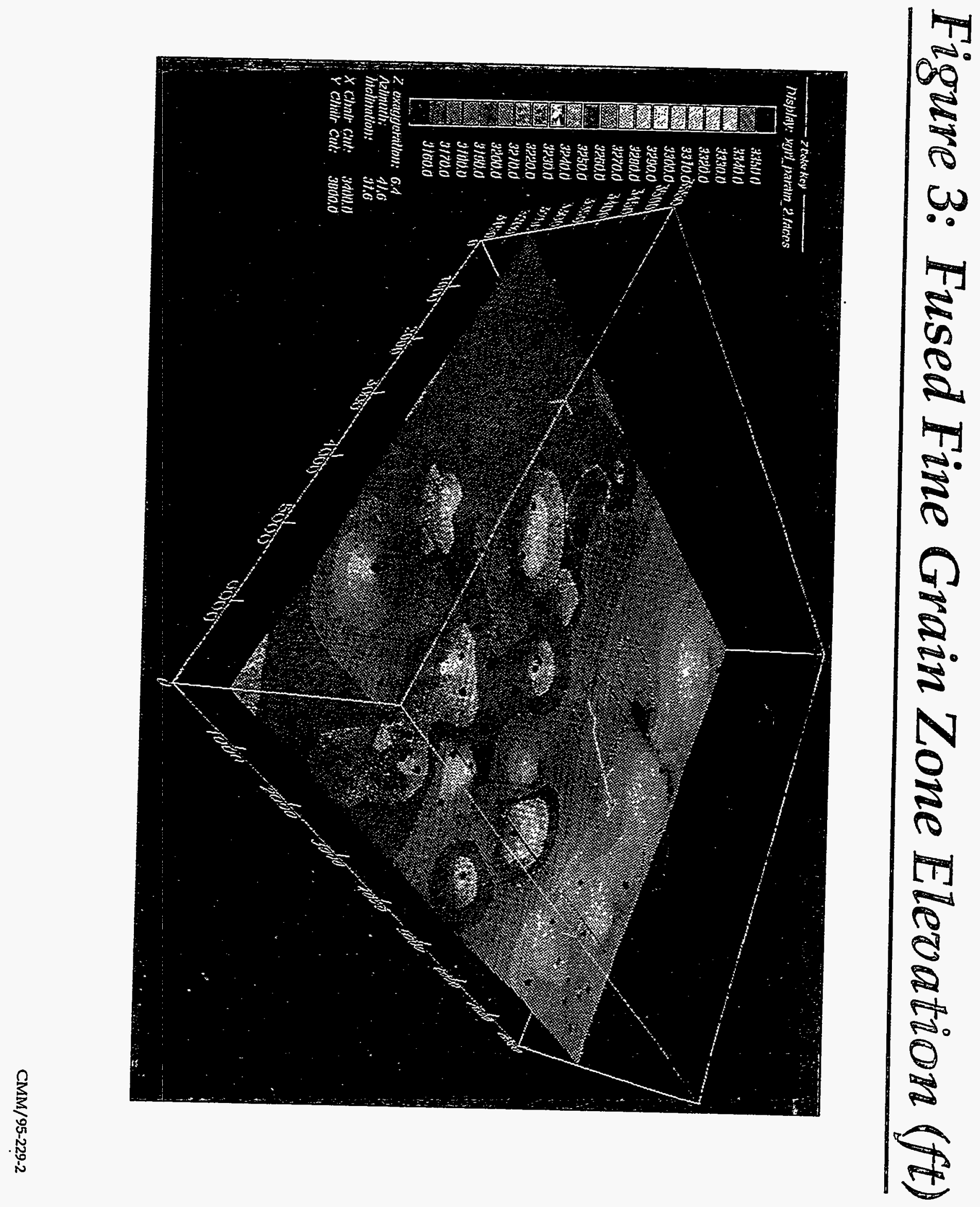




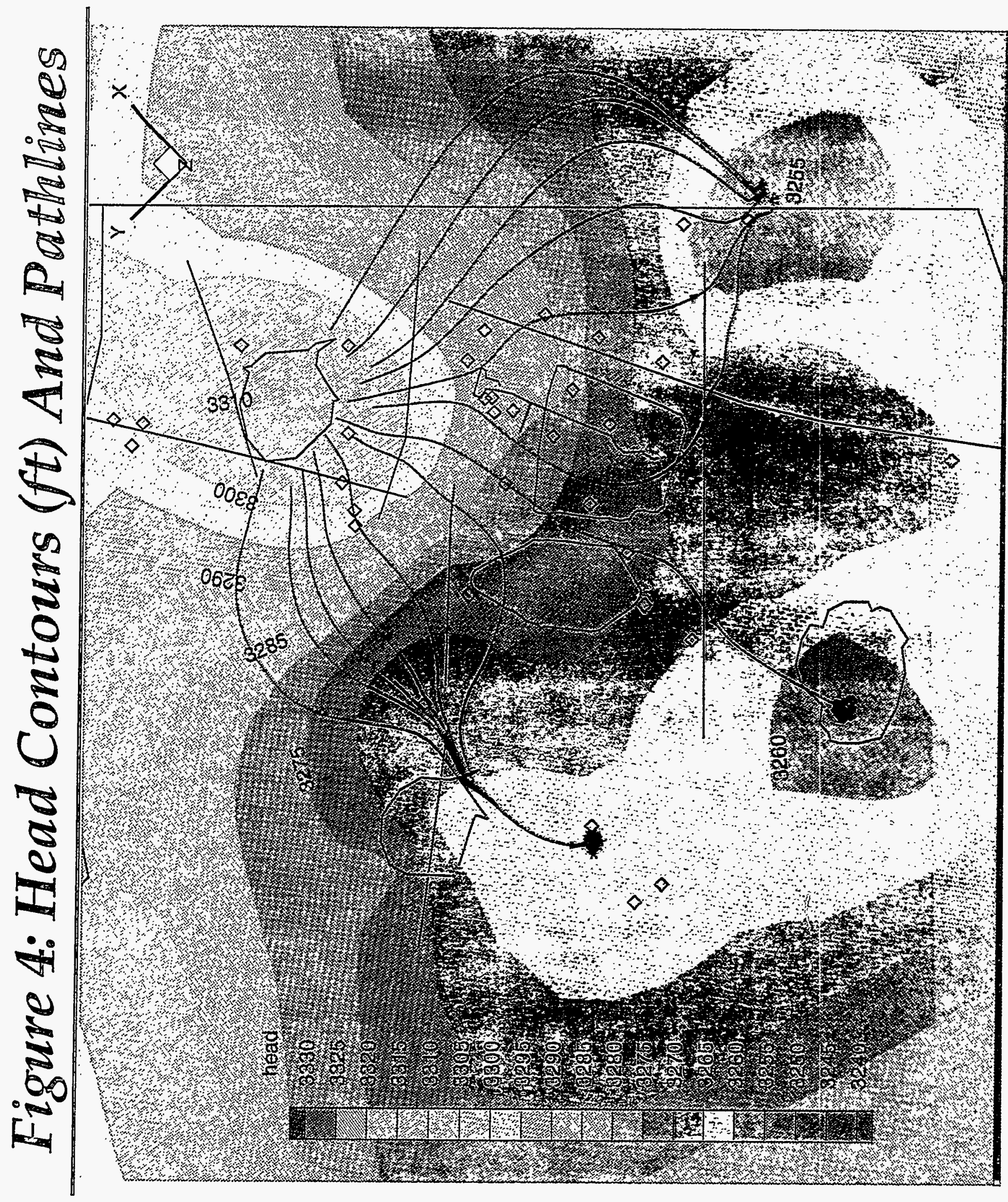




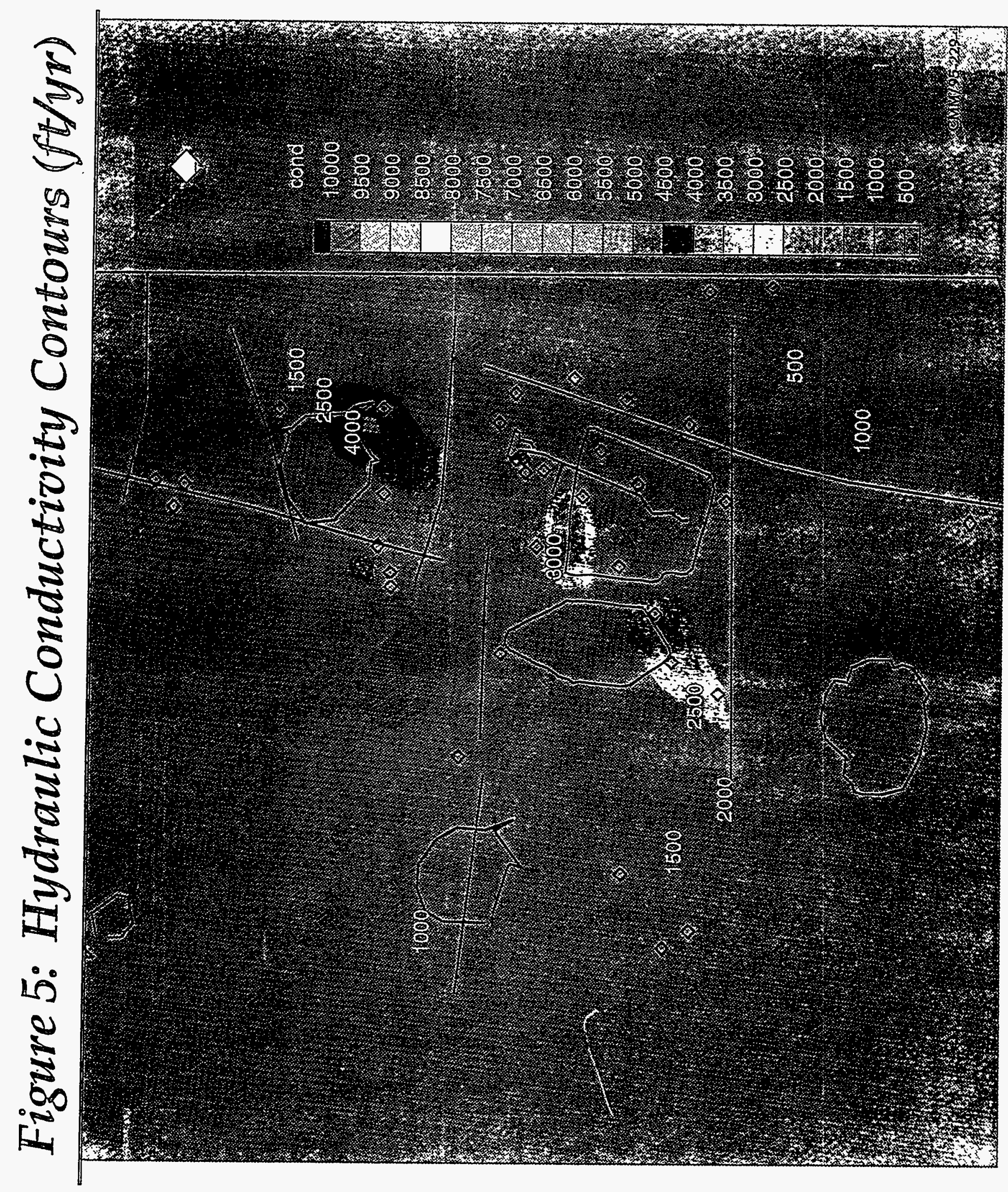




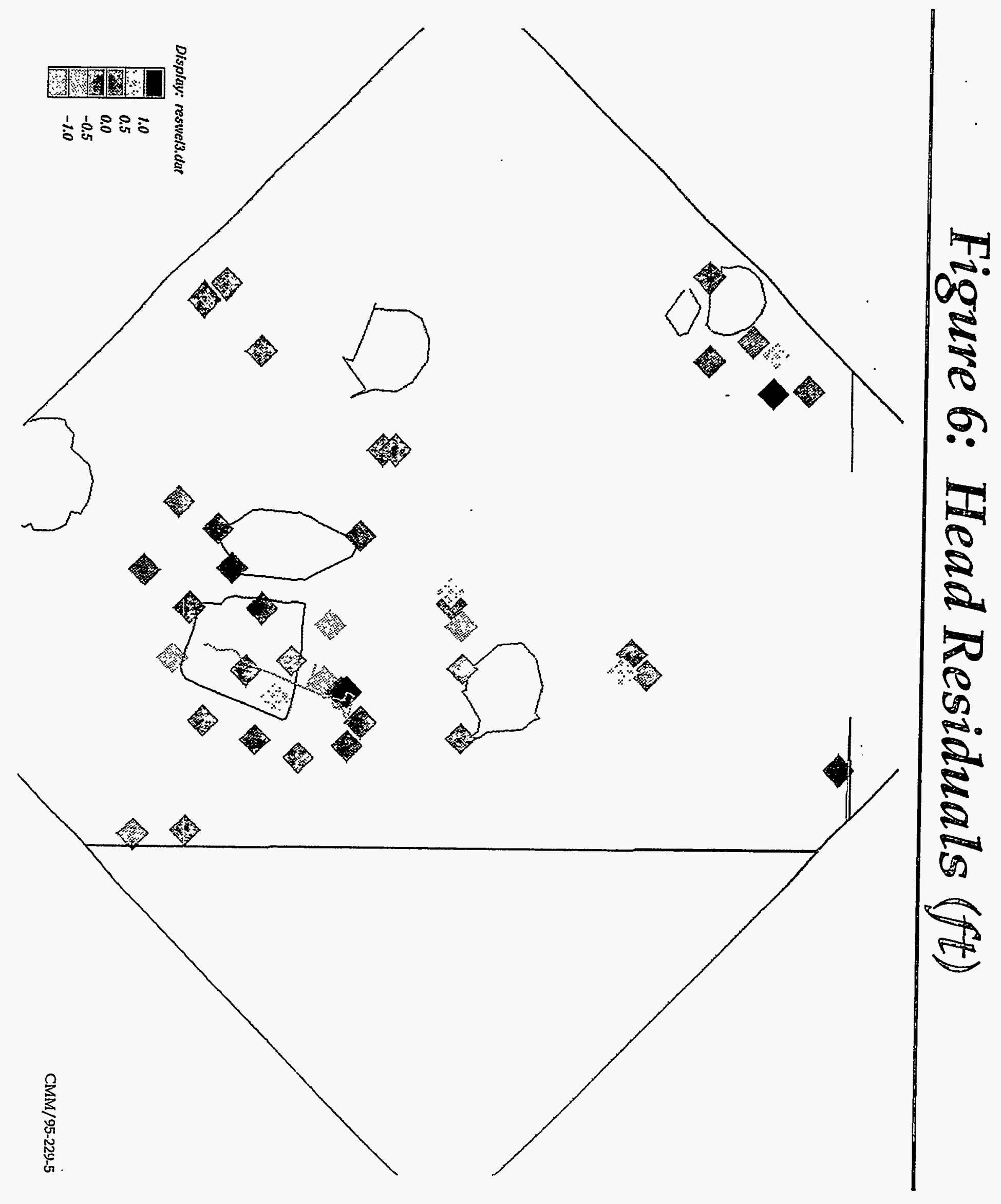

